East African Medical Journal Vol. 83 No. 1 January 2006

CONTRACEPTIVE USE AMONG IN AND OUT-OF SCHOOL ADOLESCENTS IN RURAL SOUTHWEST UGANDA

V. K. Batwala, MPH, Department of Community Health, Faculty of Medicine, Mbarara University of Science and Technology, P.O. Box 1410, Mbarara, Uganda, F. Nuwaha, PhD, Disease Control and Prevention, Makerere University, Institute of Public Health, E. M. Mulogo, MPH, MHSM, F. Bagenda, MSc, CHHM, F. Bajunirwe, MSc, Department of Community Health, Faculty of Medicine, Mbarara University of Science and Technology, P.O. Box 1410, Mbarara, Uganda and J. B. Mirembe, MBChB, Department of Paediatrics and Child Health, Faculty of Medicine, Mbarara University of Science and Technology, P. O. Box 1410, Mbarara, Uganda

Request for reprints to: Dr. V. K. Batwala, Department of Community Health, Faculty of Medicine, Mbarara University of Science and Technology, P. O. Box 1410, Mbarara, Uganda

\title{
CONTRACEPTIVE USE AMONG IN AND OUT-OF SCHOOL ADOLESCENTS IN RURAL SOUTHWEST UGANDA
}

\author{
V. K. BATWALA, F. NUWAHA, E. M. MULOGO, F. BAGENDA, F. BAJUNIRWE and \\ J. B. MIREMBE
}

\begin{abstract}
Objective: To compare the level of contraceptive use among in and out-of school rural Ugandan adolescents.

Design: Cross sectional survey.

Setting: Mbarara district.

Subjects: Five hundred in-school and 220 out-of school adolescents aged 15-19 years. Main outcome measure: Contraceptive use.

Results: Contraceptive prevalence was $171(23.8 \%)$, with $99(19.8 \%)$ among in-school and $72(32.7 \%)$ in out-of school $(\mathrm{OR}=0.8,95 \% \mathrm{CI}=\mathbf{0 . 5 - 1 . 3})$. Of the 286 who had had sexual intercourse, $171(59.8 \%)$ were current users with $99(57.9 \%)$ in-school and 72 $\mathbf{( 4 2 . 1 \% )}$ out-of school. The predominant method was the male condom with $80(56.7 \%)$ in-school and $61(43.3 \%)$ out-of-school $(p=0.3)$. Sixty five $(67 \%)$ of in-school aged 1819 used contraceptives compared to those less than 18 years $(\mathrm{OR}=0.4,95 \% \mathrm{CI}=0.2-$ 0.8). The out-of school who were urban residents $51(75 \%)$ were more likely to use contraceptives $(\mathrm{OR}=\mathbf{0 . 3}, \mathbf{9 5 \%} \mathrm{CI}=\mathbf{0 . 1 - 0 . 6})$. Out-of school with secondary education $\mathbf{3 7}(\mathbf{8 4 . 1 \%})$ were more likely to use contraceptives $(\mathrm{OR}=\mathbf{0 . 2}, \mathbf{9 5 \%} \mathrm{CI}=\mathbf{0 . 1 - 0 . 5})$. Cost was a barrier for contraceptive use among in-school users 37(77.1\%) $(\mathrm{OR}=\mathbf{2 . 6}$, 95\% $\mathrm{CI}=1.7$ 5.4). Stigma surrounding their sexual activity was a barrier to out-of school $25(58.1 \%)$ $(\mathrm{OR}=0.4,95 \% \mathrm{CI}=0.2-0.8)$.

Conclusion: Contraceptive use among rural sexually active adolescents is low although the prevalence is higher in out-of school. Reorientation of contraceptive services to make them more accessible through strengthening of school health programme and establishment of out-of school adolescent health programme are urgently needed.
\end{abstract}

\section{INTRODUCTION}

Despite the expansion of national health infrastructures, the reproductive health profile of many developing countries populations remain poor. Expansion of family planning services and contraceptive method choice has yet to meet existing contraceptive needs. About 75 million of the estimated 180-200 million pregnancies that occur in the world annually are reportedly unintended, and a high proportion of these occur in adolescence (1).

The steadily decreasing age of menarche and increasing age at marriage have created an everwidening window of time for premarital sexual intercourse and pregnancies. Even in countries where age at first intercourse has risen, age at marriage has risen faster. For married youth, contraception remains rare in many countries, and social norms pressure young couples to start childbearing immediately, with little subsequent spacing of births. Information about how to prevent pregnancy and sexually transmitted infections (STIs), including Human Immunodeficiency Virus (HIV) should emphasise the importance of abstinence as the only way to eliminate the risk of pregnancy and contracting an STI.

For avoiding STIs, they especially need condoms(2). The actual use of contraceptive services is a function of motivation and access to these services regardless of the age group involved, but majority of teenage women living in developing countries have unmet need for family planning (3).

Uganda with the total fertility rate of 6.9 births per woman is one of the highest among countries in Eastern and Southern Africa. Childbearing starts early with a mean number of children ever born among adolescents aged 15-19 years being 0.3 live births per 
woman(4). Teenage pregnancy(5) and motherhood has been a major health and social concern in Uganda. Teenage pregnancy is singled out because of its association with higher morbidity and mortality for both the mother and the child. In addition, with the current school practice, pregnant girls have to terminate their education, which affects the health of the mother and the child through loss of socio-economic opportunities.

In Uganda, $96.2 \%$ of currently married adolescent females and $100 \%$ males know of at least one modern contraceptive method, and $21.5 \%$ of married adolescent females aged 15-19 have used a contraceptive method with $18.4 \%$ being a modern contraceptive (4). Information on contraceptive use by single-sexually experienced adolescents is sparse. Information distinguishing the use of contraceptives by the in-school and the out-ofschool Ugandan adolescents is also lacking. This article compares the level of contraceptive use among rural in-school and out-of school adolescents in southwestern Uganda.

\section{MATERIALS AND METHODS}

Study design and setting: This was a cross sectional study conducted in Mbarara district located in southwest Uganda. The district has a total population of $1,089,051$. An estimated $92 \%$ of the population inhabit rural areas. The smallest unit of social organisation from colonial times is a village (300-500 people).

The national health policy created the Health SubDistricts as the health service zones within each district. They are functional sub-divisions of the district health system aimed at improving the quality and management of routine health service delivery, increasing equity of access to essential health services and to foster community involvement in planning, management and delivery of basic health care. Communities' owned resource persons attached to health centres provide community related health (promotive and preventive) services. Health sub-districts conduct school health outreaches where adolescent health is discussed including reproductive health. The leadership of the health sub-district is based at an existing hospital or up graded health centre.

The Uganda government advocates for complete sexual abstinence before marriage. The goal is to effectively protect young people against both pregnancy and HIV infection. However, those who cannot abstain are free to use contraceptives while having sexual intercourse. About half of contraceptives come from public health facilities that constitute $90 \%$ of health units within the district. Private for profit health facilities including hospitals, clinics and drug shops also provide contraceptive services. Faith-based health facilities excluding those under the Catholic Church also provide contraceptive services. Stand-alone organisations such as the Family Planning Association of Uganda and the acquired Immunodeficiency Syndrome (AIDS) information centre also provide contraceptive services. The latter provides condoms to clients as part of the strategy to prevent the spread of HIV/AIDS among sexually active individuals. Traditional birth attendants (TBAs) provide antenatal services as well as pregnancy related counselling to rural women who visit their establishments. The Uganda Health Policy recognises TBAs as members of the private sector involved in the provision of health care in the country. To this effect, the government supports improved delivery of TBA services through training programmes and provision of basic delivery kits (mackintosh, gloves, etc).

Mbarara District has one Youth Centre (Family Planning Association of Uganda Youth Centre) providing Adolescents Friendly Reproductive Health Services. The centre is situated within Mbarara Municipality. The centre provides family planning counselling - methods and their side effects. It primarily advocates abstinence, but also provides oral contraceptives (pills) and condoms. However, currently no policy exists for condom dispensing at youth clubs. Other static services provided include: laboratory testing (sexually transmitted diseases, malaria, typhoid, and other common infections), voluntary counselling and testing for HIV, treatment of minor illnesses, antenatal and postnatal care, immunisation for children born to adolescents, and youth recreation activities including music, library services and in- and out-door games. The Youth Centre outreach activities for inschool within the district include music, dance and drama to create awareness of the services provided by the centre. The "Transect Trade Programme" - an outreach programme currently piloted in two villages within the municipality provides services to out-of school adolescents (targets bar maids and commuter motorcyclists).

Ethical considerations: The study was approved by Mbarara University of Science and Technology Faculty of Medicine Research and Ethics Committee, and Mbarara University Institutional Review Board in 2004. It was also cleared by Mbarara District Education Department and the Local Councils of the selected villages. In schools, permission to conduct the study was sought from the school authorities. Adolescents below 18 years of age were given consent forms to take to their parents. Only those who returned signed forms were enrolled into the study. In the villages, consent was sought from the parents at home as well as the out-of school adolescents. None of the study participants were obliged to participate in the study. Participants' names were not required on the questionnaire.

Data collection and analysis: The study was implemented in 2004. Seven secondary schools were randomly selected from five of the ten Health Sub-Districts in Mbarara district. These included two boarding schools (one male and the other female single sex school) and five dual sex, mixed day and boarding-schools. An average of 71 adolescents aged 15-19 years in each school were randomly enrolled through use of random numbers and class lists as sampling frame. A subtotal of 500 in-school adolescents was enrolled.

Two hundred and twenty out-of school adolescents in the same age group residing in the villages surrounding the selected schools were also enrolled. Lists of households with out-of school were obtained from the village local leaders and adolescents enrolled using random numbers. Only one adolescent was interviewed per household. Where a household had two or more eligible adolescents, only one was randomly selected and interviewed. Therefore a total of 720 adolescents constituted the study sample.

Information was collected by use of pretested selfadministered questionnaire but with guidance of the investigators. For the out-of school adolescents who were unable to read and write, the interviewer-administered technique was employed. Social, demographic and contraceptive data on both modern and traditional methods were collected. The contraceptives included the following: calendar/rhythm, withdrawal, male and female condom, spermicide, diaphragm, oral contraceptive/pill, injectable, female/male sterilisation, 
and any other methods they considered a contraceptive that they used.

The questionnaire was pre-coded prior to data entry. Data were cleaned and errors checked and all missing data coded and excluded in the final analysis. Analysis was done using the Statistical Package for Social Sciences programme version 10. Logistic regression was applied and Odds Ratios (OR) and the 95\% Confidence Intervals (95\% CI) were calculated. The t-test was used to compare the mean age and the age at first sexual encounter. The Chi-square test was used to compare proportions with p-value set at 0.05 level of significance.

\section{RESULTS}

Socio-demographic characteristics: Males and females were almost equally represented in the sample (361 or $50.1 \%$ vs. 359 or $49.9 \%$ respectively). Four hundred and twenty four $(58.9 \%)$ of the sample had never had sexual intercourse and ten adolescents among out-of school were married. The two categories ("never had sex" and "married") were excluded from further analysis leaving $286(39.7 \%)$ in the final sample of whom 171(59.8\%) were in-school and 115(40.2\%) were out-of school. The overall mean age was 17.6 ( $\pm 1.2 \mathrm{SD})$ years, but it was slightly lower (17.5 years) for in-school than out-of school (17.7 years) $(\mathrm{p}=0.16$, t-test). The mean age was slightly higher for male (17.6 years) than female (17.5 years) $(\mathrm{p}=0.4)$. The mean age at first sexual intercourse was $15.2( \pm 2.4 \mathrm{SD})$ years, lower (15.0 years) among in-school than in out-of school ( 15.5 years $)(p=0.13$, t-test $)$. Males initiated sex at an earlier age (15.1 years) than females (15.6 years) $(\mathrm{p}=0.06)$. For the out-of school, the median duration while not in school was $2.8( \pm 2 \mathrm{SD})$ years. Table 1 shows the socio-demographic profile of adolescents who were single, but had had sex.

The in-school $106(69.7 \%)$ significantly resided in rural area while the out-of school $68(51.5 \%)$ were more concentrated in urban areas $(\mathrm{OR}=2.5,95 \% \mathrm{CI}=1.5-4)$. Adolescents living with guardians were about eight times more likely to be out-of school $60(69 \%)(\mathrm{OR}=7.7$, 95\% CI=4.3-13.6).

Whereas all in-school were attending secondary schools, the composition of the out-of school adolescents was as follows: $10(8.7 \%)$ never went to school, $61(53.0 \%)$ attained primary education and only $44(38.3 \%)$ attended up to secondary level. The out-of school were 2.4 times more likely to have multiple sexual partners compared to in-school $(\mathrm{OR}=2.4$, 95\% CI=1. 4-4.1).

Ever-used and current use of contraceptives: The overall contraceptive prevalence was $171(23.8 \%)$, with $99(19.8 \%)$ among in-school and $72(32.7 \%)$ among outof school $(\mathrm{OR}=0.8,95 \% \mathrm{CI}=0.5-1.3)$. Of those who had ever had sex, 178(62.2\%) had ever used some form of contraception; while 171(59.8\%) were current users. Of those who had ever used contraceptives, 102(57.3\%) were in-school and 76(42.7\%) were out-of school (OR=0.8, $95 \% \mathrm{CI}=0.5-1.2)$. For current users, 99(57.9\%) were inschool and $72(42.1 \%)$ were out-of school $(\mathrm{OR}=0.8$, $95 \% \mathrm{CI}=0.5-1.3)$. There was no statistically significant difference between ever-used and current users when the in-school and out-of school groups were compared.

Table 1

Socio-demographic profile of study participants $(n=286)$

\begin{tabular}{|c|c|c|c|}
\hline Predictor & $\begin{array}{l}\text { In-school } \\
\text { No. }(\%)\end{array}$ & $\begin{array}{l}\text { Out of school } \\
\text { No. }(\%)\end{array}$ & $\begin{array}{l}\text { Odds Ratio } \\
(95 \% \mathrm{CI})\end{array}$ \\
\hline \multicolumn{4}{|l|}{ Gender } \\
\hline Male & $118(58.7)$ & $83(41.3)$ & \\
\hline Female & $53(62.4)$ & $32(37.6)$ & $0.9(0.5-1.4)$ \\
\hline \multicolumn{4}{|l|}{ Age-group (years) } \\
\hline$<18$ & $73(62.9)$ & $43(37.1)$ & \\
\hline $18-19$ & $97(57.7)$ & $71(43.2)$ & $1.2(0.8-2.0)$ \\
\hline \multicolumn{4}{|c|}{ Age at first sexual intercourse (years) } \\
\hline$<18$ & $130(57.5)$ & $96(42.5)$ & \\
\hline 18-19 & $28(62.2)$ & $17(38.8)$ & $0.8(0.4-1.6)$ \\
\hline \multicolumn{4}{|l|}{ Residence } \\
\hline Rural & $106(69.7)$ & $46(30.3)$ & \\
\hline Urban & $64(48.5)$ & $68(51.5)$ & $2.5(1.5-4.0)^{*}$ \\
\hline \multicolumn{4}{|l|}{ Parent/guardian } \\
\hline Biological parents & 144(77.6) & $41(22.4)$ & \\
\hline Guardian & $27(31.0)$ & $60(69.0)$ & 7.7(4.3-13.6)* \\
\hline \multicolumn{4}{|l|}{ Religion } \\
\hline Catholic & $79(70.5)$ & $33(29.5)$ & \\
\hline Other & $92(53.2)$ & $88(46.8)$ & $2.1(1.3-3.5)^{*}$ \\
\hline \multicolumn{4}{|l|}{ Education level } \\
\hline None/primary & - & $67(100)$ & \\
\hline Secondary & $171(79.5)$ & $44(20.5)$ & $\S$ \\
\hline Two or more life sexual partners & $77(49.0)$ & $80(51.0)$ & $2.4(1.4-4.1)^{*}$ \\
\hline
\end{tabular}


Table 2 shows the contraceptive methods that adolescents in our study were using. The methods included: calendar/rhythm, withdrawal, condom, oral contraceptive (pill) and injectable (Depo-Provera). Majority were using the male condom with $80(56.7 \%)$ in-school and 61(43.3\%) out-of school. The calendar and withdrawal methods were mostly used by the inschool $11(84.6 \%)$ and $8(72.4 \%)$ respectively. There was no statistically significant difference between the in-school and the out-of school with regard to use of any of the above methods. Only one adolescent in the out-of school category was using a diaphragm. None of the adolescents used spermicide and female condom.

Table 2

Contraceptive methods of current users (in-school $n=99$, out-of school $n=72$ )

\begin{tabular}{llll}
\hline Method & $\begin{array}{l}\text { In-school } \\
\text { No. }(\%)\end{array}$ & $\begin{array}{l}\text { Out-of school } \\
\text { No. }(\%)\end{array}$ & $\begin{array}{l}\text { P-value* } \\
\text { (two-tailed) }\end{array}$ \\
\hline Calendar & $11(84.6)$ & $2(15.4)$ & 0.1 \\
Withdrawal & $8(72.4)$ & $3(27.3)$ & 0.5 \\
Condom & $80(56.7)$ & $61(43.3)$ & 0.3 \\
Pill & $1(20)$ & $4(80)$ & 0.2 \\
Injection & $2(50)$ & $2(50)$ & 1.0 \\
Other $\psi$ & None & $1(100)$ & $\S$ \\
\hline
\end{tabular}

*Fisher's Exact Test, $\psi$ Diaphragm and Spermicide
Table 3 and 4 show the predictors examined for influence on use of contraceptives by adolescents stratified by in and out-of school categories. The predictors included gender, age-group, age at first sexual intercourse, parent/guardian, place of residence, religion, life sexual partners, and for the out-of school - level of education and duration while out of school.

For the in-school, only age was significant predictor of contraceptive use. In-school adolescents in the 1819 year age-group 65(67\%) used contraceptives more than those less than 18 yeas of age $33(45.2 \%)(\mathrm{OR}=0.4$, $95 \% \mathrm{CI}=0.2-0.8)$. There was no statistically significant difference between in-school users and non-users when other predictors were entered into the logistic regression model.

For the out-of school, place of usual residence and level of education were significant predictors of contraceptive use. Fifty one $(75 \%)$ of adolescents living in urban areas were contraceptive users compared to $20(43.5 \%)$ who resided in rural areas $(\mathrm{OR}=0.3,95 \% \mathrm{CI}=0.1-0.6)$. Those who attained secondary education $37(84.1 \%)$ were more likely to use contraceptives compared to those who had never gone to school or had only attained primary education $(\mathrm{OR}=0.2,95 \% \mathrm{CI}=0.1-0.5)$. There was no statistically significant difference between out-of school users and non-users when other predictors were considered.

Table 3

Current contraceptive use among rural Uganda in-school adolescents (Using $n=99$, Not using $n=72$ )

\begin{tabular}{|c|c|c|c|}
\hline Predictor & $\begin{array}{l}\text { Using } \\
\text { No. }(\%)\end{array}$ & $\begin{array}{l}\text { Not using } \\
\text { No. }(\%)\end{array}$ & $\begin{array}{l}\text { Odds Ratio } \\
(95 \% \text { CI })\end{array}$ \\
\hline \multicolumn{4}{|l|}{ Gender } \\
\hline Male & $71(60.2)$ & $47(39.8)$ & \\
\hline Female & $28(52.8)$ & $25(47.2)$ & $1.4(0.7-2.6)$ \\
\hline \multicolumn{4}{|l|}{ Age-group (years) } \\
\hline$<18$ & $33(45.2)$ & $40(54.8)$ & \\
\hline $18-19$ & $65(67.0)$ & $32(33.0)$ & $0.4(0.2-0.8)^{*}$ \\
\hline \multicolumn{4}{|l|}{ Age at first sexual intercourse (years) } \\
\hline$<18$ & $72(55.4)$ & $58(44.6)$ & \\
\hline $18-19$ & $18(64.3)$ & $10(35.7)$ & $0.7(0.3-1.6)$ \\
\hline \multicolumn{4}{|l|}{ Parent/guardian } \\
\hline Biological parent(s) & $82(57.7)$ & $60(42.3)$ & \\
\hline Guardian & $15(56.6)$ & $12(44.4)$ & $1.2(0.5-2.5)$ \\
\hline \multicolumn{4}{|l|}{ Place of residence } \\
\hline Rural & $59(55.7)$ & $47(44.3)$ & \\
\hline Urban & $39(60.9)$ & $25(39.1)$ & $0.8(0.4-1.5)$ \\
\hline \multicolumn{4}{|l|}{ Religion } \\
\hline Catholic & $41(51.9)$ & $38(48.1)$ & \\
\hline Other & $58(63.0)$ & $34(37.0)$ & $0.6(0.3-1.2)$ \\
\hline Two or more life sexual partners & $45(58.4)$ & $32(41.6)$ & $0.8(0.4-1.6)$ \\
\hline
\end{tabular}

*Statistically significant 
Table 4

Current contraceptive use among rural Uganda out-of school adolescents (Using $n=72$, Not using $n=43$ )

\begin{tabular}{|c|c|c|c|}
\hline Predictor & $\begin{array}{l}\text { Using } \\
\text { No. (\%) }\end{array}$ & $\begin{array}{l}\text { Not using } \\
\text { No. }(\%)\end{array}$ & $\begin{array}{l}\text { Odds Ratio } \\
(95 \% \quad \mathrm{CI})\end{array}$ \\
\hline \multicolumn{4}{|l|}{ Gender } \\
\hline Male & $50(60.2)$ & $33(39.8)$ & \\
\hline Female & $22(68.8)$ & $10(31.2)$ & $0.7(0.3-1.6)$ \\
\hline \multicolumn{4}{|l|}{ Age-group (years) } \\
\hline$<18$ & $24(55.8)$ & $19(44.2)$ & \\
\hline $18-19$ & $47(66.2)$ & $24(33.8)$ & $0.7(0.3-1.4)$ \\
\hline \multicolumn{4}{|l|}{ Age at first sexual intercourse (years) } \\
\hline$<18$ & $61(63.5)$ & $35(36.5)$ & \\
\hline $18-19$ & $10(58.8)$ & $7(41.2)$ & $1.2(0.4-3.5)$ \\
\hline \multicolumn{4}{|l|}{ Parent/guardian } \\
\hline Biological parent(s) & $25(61.0)$ & $16(39.1)$ & \\
\hline Guardian & $37(61.7)$ & $23(38.3)$ & $0.9(0.4-2.2)$ \\
\hline \multicolumn{4}{|l|}{ Place of residence } \\
\hline Rural & $20(43.5)$ & $26(56.5)$ & \\
\hline Urban & $51(75.0)$ & $17(25.0)$ & $0.3(0.1-0.6)^{*}$ \\
\hline \multicolumn{4}{|l|}{ Religion } \\
\hline Catholic & $18(54.5)$ & $15(45.5)$ & \\
\hline Other & $53(65.4 ?$ & $28(34.6)$ & $0.6(0.3-1.5)$ \\
\hline \multicolumn{4}{|l|}{ Education level } \\
\hline None/primary & $33(49.3)$ & $34(50.7)$ & \\
\hline Secondary and above & $37(84.1)$ & $7(15.9)$ & $0.2(0.1-0.5)^{*}$ \\
\hline Two or more life sexual partners & $51(63.8)$ & $29(36.2)$ & $0.8(0.3-1.9)$ \\
\hline \multicolumn{4}{|l|}{ Duration while out-of school } \\
\hline$<2$ years & $27(69.2)$ & $12(30.8)$ & \\
\hline$\geq 2$ years & $39(66.1)$ & $20(33.9)$ & $1.2(0.5-2.7)$ \\
\hline
\end{tabular}

*Statistically significant

Table 5

Barriers influencing contraceptive use (in-school $n=171$, out-of school $n=115$ )

\begin{tabular}{llll}
\hline Barrier & $\begin{array}{l}\text { In-school } \\
\text { No. }(\%)\end{array}$ & $\begin{array}{l}\text { Out-of school } \\
\text { No. }(\%)\end{array}$ & $\begin{array}{l}\text { Odds Ratio } \\
(95 \% \mathrm{CI})\end{array}$ \\
\hline Fear side effects & $61(66.3)$ & $31(33.7)$ & $1.5(0.9-2.5)$ \\
Stigma & $18(41.9)$ & $25(58.1)$ & $0.4(0.2-0.8)^{*}$ \\
Expensive & $37(77.1)$ & $11(22.9)$ & $2.6(1.7-5.4)^{*}$ \\
Lack of contraceptive varieties & $6(28.6)$ & $15(71.4)$ & $0.2(0.1-0.6)^{*}$ \\
Partner refusal & $46(62.2)$ & $28(37.8)$ & $1(0.7-2.0)$ \\
Want to feel sensation & $2(25)$ & $6(75)$ & $\S$ \\
Lack of contraceptive knowledge & $1(9.1)$ & $10(90.9)$ & $\S$ \\
Unprogrammed encounter & - & $2(100)$ & $\S$ \\
\hline
\end{tabular}

*Statistically significant, § not calculated

Barriers to contraceptive use: Table 5 compares the barriers influencing contraceptive use between the two study groups. Cost of contraceptives was a barrier to in-school 37(77.1\%) compared to out-of school users $11(22.9 \%)(\mathrm{OR}=2.6,95 \% \mathrm{CI}=1.7-5.4)$. Other barriers were: fear of contraceptive side-effects $61(66.3 \%)$ compared to $31(33.7 \%)$ and partner refusal $46(62.2 \%)$ compared to 28(37.8\%) for in-school and out-of school respectively. There was no statistically significant difference when in and out-of school contraceptive users were compared with regard to fear of side effects and partner refusal. Guilt (stigma) surrounding their sexual activity and contraceptive usage was a barrier to out-of school 25(58:1) than in-school users $18(41.9 \%)$ $(\mathrm{OR}=0.4,95 \% \mathrm{CI}=0.2-0.8)$. Lack of commonly used contraceptive varieties was a barrier to out-of school users $15(71.4 \%) \quad(\mathrm{OR}=0.2,95 \% \mathrm{CI}=0.1-0.6)$. Other barriers to out-of school were lack of appropriate 
knowledge about contraceptives $10(90.9 \%)$, desire to feel sensation of penetrative sexual intercourse $6(75 \%)$, and unprogrammed encounter.

\section{DISCUSSION}

A better understanding of the dynamic process of contraceptive use by the in-school and out-of school adolescents might lead to the development of suitable interventions targeting these two vulnerable populations. We have estimated that contraceptive use among the single-sexually exposed rural Ugandan adolescents aged 15-19 years is low. This contraceptive prevalence is lower than that reported in other studies $(6,7)$. The prevalence among the in-school was however similar to that reported among secondary school adolescents in Nigeria(8).

Although there was no statistically significant difference in contraceptive use between the two study groups, the out-of school were more likely to use contraceptives. Our findings suggest that there is need for reorientation of the contraceptive services to focus on adolescents and to make these services more available and accessible to them.

For the in-school, only age was a significant predictor of contraceptive use. However, the mean age at first sexual intercourse reported in the current study was far below the age of consent (18 years) in Uganda. It has been reported elsewhere that early sexual debut can place adolescents at increased risk of unintended pregnancy, HIV, and other sexually transmitted infections (STIs). Youth who begin sexual activity early appear more likely to have sex with high-risk partners or multiple partners and are less likely to use condoms $(9,10)$. The observed association between contraceptive use and age may be a reflection of exposure to knowledge. This finding illustrates the need for accurate information about contraceptive methods presented in an age-appropriate manner before they are likely to become sexually active. Orientation and assistance in selecting the best method should be provided in places accessible to young people, in a language they can understand.

For the out-of school, only place of residence and level of education of adolescent were significant predictors of contraceptive use. These factors are proxy variables of socio-economic status. This finding is consistent with that reported in Peru where contraceptive use was strongly related to contact with urban centres and the economic status of the Peruvian population(11), and in another study where secondary or higher education and urban residence strongly influenced contraceptive use (12). It has also been argued that the strong association of contraceptive use with urban environments where there are private health facilities is perhaps because these facilities improve the availability of a variety of contraceptive methods(13).
Rhythm and withdrawal were mostly used by inschool. This was not surprising baring in mind that there are abrupt checks for unauthorised personal effects in Ugandan schools. Storing modern contraceptives (for example condom and oral contraceptives) may be interpreted as immoral behaviour and this act would easily attract dismissal of the adolescent from school. Majority of in-school were staying with their parents, and sharing the same house, where normally parents inspect the bedrooms of young people. The school and home environments are likely to put the school going adolescent at risk of having sexual intercourse without using the modern contraceptives. Given that cost of contraceptives was a reported barrier among the inschool, this also contributes to preference for the rhythm and withdraw methods. Majority of the out-of school on the other hand were staying with other relatives who may not care so much about the sexual activity and contraceptive usage by young people. This is evidenced from the fact that the out-of school had more multiple sexual partners. Rhythm and withdrawal are relatively ineffective for inexperienced adolescents and should be replaced by more effective methods. Abstinence should be promoted, especially among the youngest and those who have never had sex. Condoms are the ideal methods for adolescents because of absence of side effects, and protection against sexually transmitted diseases and HIV. Promotion of condom use requires reducing the cost and combating some misconceptions about sex and contraception.

In rural southwestern Uganda, the contraceptive services are urgently needed because of the young age at initiation of sexual activity, low rate of contraceptive usage among sexually active adolescents, cost of contraceptives, perceived fear of contraceptive sideeffects, lack of agreement on contraceptive use between partners, guilt/stigma surrounding their sexual activity and contraceptive usage, unavailability of contraceptive method choices to choose from, desire to feel sensation of penetrative sexual intercourse and the knowledge deficit regarding contraceptives.

In conclusion contraceptive use among rural Ugandan adolescents is low. More out-of school were contraceptive users, although not significantly different from the in-school. Age was a significant predictor of contraceptive use among in-school while place of residence and level of education of the adolescent were significant predictors for the out-of school.

Whereas abstinence should remain the main stay of health education messages to adolescents, contraceptive services should be made more accessible to those who are sexually active. Strengthening of the school health programme and establishment of out-of school adolescent health programmes by the Health Sub-Districts and scaling up of outreach activities by the Family Planning Association of Uganda, Mbarara Youth Centre are urgently needed. 


\section{ACKNOWLEDGEMENTS}

This study received financial support from the collaboration between Lund University in Sweden and Mbarara University of Science and Technology (The LUMUST-Project). We are grateful to adolescents who participated in the study.

\section{REFERENCES}

1. UNDP/UNFPA/WHO/WORLDBANK Special Program of Research, Development and Training in Human Reproduction: Social science initiative on quality of care and reproductive health, 2003.

2. Global Health Technical Briefs. Youth and Contraception: Needs and Challenges. http://www.maqweb.org/techbriefs/ tb9youth.shtml Accessed August 09, 2005.

3. McDevitt, M. T., Adlakha, A., Fowler, B. T., et al. Trends in adolescent fertility and contraceptive use in the developing world. United States Bureau of the Census, Report IPC/95-1. United States Government Printing Office, Washington, DC, 1996.

4. Uganda Bureau of Statistics (UBOS) and ORC Macro. 2001. Uganda Demographic and Health Survey 20002002. Calverton; Maryland, USA: UBOS and ORC Macro.
5. Mbonye, A. K. Disease and health seeking patterns among adolescents in Uganda. Int. J. Adolesc. Med. Health. 2003; 15: $105-112$.

6. Agyei, A. K. and Epema, E. Adolescent fertility in Kampala, Uganda: knowledge, perceptions and practice. Biol. Soc. 1990; 7: 203-214.

7. Zhang, L. Y., Jejeebhoy, S., Shah, I. H., et al. Access to contraceptive services among unmarried young people in the north-east of China. Eur J. Contracept. Reprod. Health Care. 2004; 9: 147-154.

8. Ootoide, F., Oronsaye, E. E. and Okonofua, V. Sexual behaviour and contraceptive use among secondary school adolescents in Benin City, Nigeria. J. Obstet. Gynaecol. 2001; 21: 298-302.

9. World Health Organization. The context of young people's sexual relations. Progress in Reproductive Health Research. 2000, 53: 2-4.

10. Global Health Technical Briefs. Abstinence and Delayed Sexual Initiation for Youth. http://www.maqweb.org/ techbriefs/tb8abstinence.shtml Accessed August 09, 2005.

11. Tucker, G. M. Barriers to modern contraceptive use in rural Peru. Stud. Fam. Plann. 1986; 17: 308-316.

12. Agyei, W. K. and Migadde, M. Demographic and sociocultural factors influencing contraceptive use in Uganda. J. Biosoc. Sci. 1995 ; 27: 47-60.

13. Katende, C., Gupta, N. and Bessinger, R. Facility-level reproductive health interventions and contraceptive use in Uganda. Int. Fam. Plan. Perspect. 2003; 29: 130-137.

\section{THE KENYA ASSOCIATION OF DERMATOLOGISTS}

\section{Conference Announcement and call for Papers}

The Biannual KAD Scientific Conference

Dates: 31st March - 2nd April 2006

Theme: 'Dermatology: Looking Ahead'

Deadline for acceptance of Abstracts: 31st January 2006

Contact:wimalingat@hotmail.com

P.O. Box 45754-00100

Tel: 343157 or $0721-653514$ 